\title{
Critical Appraisal of CSR activities in India
}

\author{
Clayton Fonceca ${ }^{1}$ and A. Umesh Samuel Jebaseelan ${ }^{2}$ \\ ${ }^{1}$ PhD Resarch Scholar, ${ }^{2}$ Associate Professor, Department of Social Work Bishop Heber College Tiruchrapalli- \\ 620017
}

\begin{abstract}
Corporate Social Responsibility (CSR) with respect to Indian firms can be viewed as a strategic factor which ensures that firms have the social license to operate business, to mitigate reputational and operational risk and finally guarantee that their business keeps progressing upwards. The Government of India facilitates such top organization with the freedom and good will to extend their support towards the development of their organization and the society at large. But, how far it is being carried out is a million dollar questions that only deep probing would clarify. A survey conducted by the Sirota Survey Intelligence (2007) affirmed that employees who are satisfied with their organization's commitment to social and environmental responsibilities are likely to be positive and more productive than those working for less responsible employers and when employees are positive about their organizations' CSR commitment, their engagement rises to 86 percent.

CSR as a powerful tool enhances the brand image and reputation of the business which leads to improvement in sales and customer loyalty. By adopting the right programmes it increases the ability to attract and retain employees. Used as a right tool it offers manifold benefits both internally and externally. Industries and multinational companies should play a philanthropic role in community development it should be genuine towards its CSR activities. The focus areas on community services should include social development schemes like educational development programmes, short term employment schemes and health care facilities. It should also focus on agricultural and environmental activities such as tree plantation drives and water resource programmes whereby, creating a better brand image not only to the public but also playing an humanistic role in catering to Mother Nature. It is high time for all other organizations which have been paying only lip service to CSR should capitalize upon the existing Human Resource Department in framing practices, procedures and policies that ensure the internalization of quality, ethics and excellence in the whole system catering to proper CSR activities.
\end{abstract}

Keywords: CSR, Corporate Social Responsibility, Organizations, Firms, Programmes;

\section{Introduction}

In India, Corporate Social Responsibility is viewed as a familiar term which is often used as leverage to top Companies to cater and promote its brand image to the public. It is a concept that some companies now a days use to cancel out their taxes and to better their own nest. The Government aim is to enable top organization with the freedom and good will for them to extend their support towards the development of their organization and the society at large. But, how far it is being carried out is a million dollar questions that only deep probing would clarify.

Corporate Social Responsibility (CSR) with respect to Indian firms can be viewed as a strategic factor which ensures that firms have the social license to operate business, to mitigate reputational and operational risk and finally guarantee that their business keeps progressing upwards. It has become so important that many organizations in India have rebranded their core values to include social responsibility. For example, Bharat Petroleum Corporation Limited has adopted 37 villages as their responsibility to develop in all walks of life. It has made efforts to make them self-reliant, providing them fresh drinking water, sanitation facilities, medical facilities, vocational training and literacy camps. Around its industrial facilities, Tata Group has created towns and cities like Jamshedpur, Mithapur, Babrala for the benefit of its employees. Cadbury India, Glaxo and Richardson Hindustan are some of the companies which are helping farmers to grow crops which in turn shall serve as raw materials for them (Tripathi \& Reddy, 2006).

\section{Review of Literature}

Various researchers have emphasized the critical importance of HR for the proper implementation of CSR activities. HR can play an important role in developing the process where the business objectives are assessed and values re-aligned to match them with the expectations of the employees.

Krishnan \& Balachandran (2004) pointed out the role of HRM in incorporating responsible practices within an organization. It is due to the lack of involvement of employees and failure to embed the socially responsible 
values into the organizational culture that many CSR initiatives inevitably fail and they just become an exercise in public relations.

A survey conducted by the Sirota Survey Intelligence (2007) affirmed that employees who are satisfied with their organization's commitment to social and environmental responsibilities are likely to be positive and more productive than those working for less responsible employers and when employees are positive about their organizations' CSR commitment, their engagement rises to 86 percent. On the other hand, when employees are negative about their employer's CSR activities, only 37 percent are highly engaged.

Agarwal (2007) stated that the adoption of HR policies, such as, periodic review of employee performance, adequate training for the workforce and career advancement norms for its personnel, creating motivation, and commitment in the workforce the organization can reap the full business benefits and become successful to the great satisfaction of all its stakeholders.

\section{CSR as a tool}

Nurturing a strong corporate culture which emphasizes Corporate Social Responsibility (CSR) values and competencies is required to achieve the synergistic benefits. CSR as a powerful tool enhances the brand image and reputation of the business which leads to improvement in sales and customer loyalty. By adopting the right programmes it increases the ability to attract and retain employees. Used as a right tool it offers manifold benefits both internally and externally.

Internally, it cultivates a sense of loyalty and trust amongst the employees. It improves operational efficiency and is often accompanied by increases in quality and productivity. It serves as a soothing diversion from the routine workplace practices and gives a feeling of satisfaction and a meaning to their lives of the employees.

Externally, it aims at establishing positive public relations and earns a special respect amongst its peers. It also provides short term employment opportunities by taking various projects like construction of parks, schools, welfare facilities, etc.

\section{Common Agendas and Programmes Covered Under CSR Initiatives}

Programmes under CSR flows from the 'factor' that drives the company to perform activities either through good will or for just tax exception. However, the philanthropic mode of CSR dominates and therefore firms prefer to contribute to welfare programs under health, education and relief mostly. It would rather critical stating that the philanthropic activities are even non- strategic as companies have failed to achieve human development goals even in their spheres of influence.

The multi-stakeholders model of CSR, overarches workplace issues, Human rights issues, customer's expectation, aspirations, supplier's issues, environment etc, this has a far way to go in our country India. The meaning and scope of CSR initiatives in our country is limited to the engagement with the community, which is voluntary action driven mostly by business needs. Programmess dealing with stakeholders are limited to compliance and there have been hardly companies seen taking voluntary and proactive actions on those counts. As regards corporate partnering with NGOs, Partners in Change (PiC)'s survey indicates that $16 \%$ companies had worked in partnership with NGOs. Companies like to make cash donations mostly. But, there are companies that have their own institutions, foundations and trusts. Alternatively, Companies get their CSR program implemented through their internal functions like HR and Corp Communication. For some companies it is the compliance with the legislation which is the driving factor, whereas some old and large companies do maintain that the philosophy of the founders to be the guiding factors for companies to undertake CSR initiatives.

\section{CSR: Industries vs Multinational companies}

Times Foundation, undertook a national survey to understand the underlying dynamics of CSR and the current situation in India together with the corporate social responsibility wing of the Bennett, Coleman \& CO. Ltd., in partnership with TNS India. The survey stated that CSR in companies like TATA and BIRLA have been imbibing the case for social good in their operations for decades long before CSR become a popular cause.

Despite the above presented survey analysis, it is sometimes contradictory, though the analysis holds good for top industrial giants the same does not apply everywhere. CSR in India is at a developing stage, sometimes being one of the least understood initiatives in the Indian industrial sector. Such industries emphasis not on social goods but rather on the policy which needs to be implemented just to show that the industry is performing CSR activities.

The number of multinational companies in the last decade has brought the global multinationals and investment houses to India for competing in the domestic and international markets. Infosys a global MNC in India has supported the development of the underprivileged sector of the society by conducting health camps regularly. Infosys as part of its CSR initiatives donates huge sums of money for medicines catering to the below the poverty line sector of the community. 
Intel a well know MNC caters more on issues pertaining to global warming and as an initiative plays an important role in tree planting activities. Global warming is a major issue gaining worldwide attention and Intel promotes programmes such as the celebration of Global Earth Day and World Environment Day to create a brand image to the public. Besides, such activities the company is also involved in several programmes catering to the rural community where computer is taught to the underprivileged sector.

Industries and multinational companies should play a philanthropic role in community development it should be genuine towards its CSR activities. The focus areas on community services should include social development schemes like educational development programmes, short term employment schemes and health care facilities. It should also focus on agricultural and environmental activities such as tree plantation drives and water resource programmes whereby, creating a better brand image not only to the public but also playing an humanistic role in catering to Mother Nature.

\section{CSR: Initiatives of HRM}

HR functions are embed in CSR values which in the corporate culture is immense and has been underlined. An organization can exhibit a better brand image in the minds of people by presenting itself as an excellent employer which cares for its people and involves them in the ambit of social responsibility. The involvement of the firm's valuable resources, the employees indicates the strategic importance of HRM in the CSR initiatives of an organization. Thus, the human resource policies form the framework of the culture in the current business management style which creates awareness towards the need to achieve the business goals in the best possible ethical manner (Agrawal, 2007).

The Human Resource department should take up the responsibility to create a formal policy that involves sustainable practices among the employees. By, creating a code of ethics the organization can stimulate social responsibility to a great extent reinforcing amongst its employees the underlying values of morale practices. Training on code of ethics is the need of the hour and should be undertaken by the organization.

Empowerment as a strategy should be left in the decision of the public on their felt needs and this becomes important when an organization has many plants or units at multiple locations around the world. Proper identification of required recourses armed with the decision making authority of the public and the public relation team would help the organization assess the needs of the people whereby implementing appropriate CSR programmes.

CSR activities should be effectively measured, evaluated and reviewed by the Human Resource department since the value added by CSR form direct results relating to economic savings and indirect results relating employee satisfaction with less employee turnover. These factors contribute to improved business performance.

\section{Conclusion}

CSR has become the topic of debate with the advent of companies increasingly relying on brand strength to add value and product differentiation, the role of CSR has become inevitable in making good business sense. The very concept and scope of CSR has been understood and articulated differently - continent to continent; country to country; companies to companies and even individually.

Successful programmes on social responsibility rely heavily on enlightened people management practices. In this context HR department is assumed to be the coordinator of CSR activities in getting the employment relationship right which is a precondition for establishing effective relationships with external stakeholders and thus can orient the employees and the organization towards a socially responsible character. There is also an increasing trend in the corporate sector which has started leveraging upon employees and their management for exhibiting their commitment towards CSR. Armed with a strong and committed organizational culture reinforced by responsible Human Resource Management practices, the organizations can achieve heights of success by improved profitability, employee morale, customer satisfaction, legal compliance and societal approval for its existence. Companies should link up their philanthropic or community development initiatives with MDGs towards achieving their goals pertaining to Corporate Social Responsibility. It is high time for all other organizations which have been paying only lip service to CSR must capitalize upon the existing Human Resource Department in framing such practices, procedures and policies that ensure the internalization of quality, ethics and excellence in the whole system. 


\section{Reference}

[1] American Psychological Association - APA, (2010), California State Library Guide, University Library, Retrieved on $24^{\text {th }}$ Oct 2012 from http://www.americanpsychologicalassociation/ californiastatelibraryguide/pdf.

[2] Agrawal Kalpana (2007). Corporate Excellence as an Outcome of Corporate Governance: Rethinking the Role and Responsibility of HRM, ICFAI Journal of Corporate Governance, Vol.VI (1): 6-16.

[3] Bhatia S (2005). Business Ethics and Corporate Governance, Deep and Deep Publications Pvt. Ltd., New Delhi.

[4] Cropanzano R, Byrne ZS, Bobocel DR, \& Rupp D E (2001). Moral virtues, fairness heuristics, social entities, and other denizens of organizational justice, Journal of Vocational Behavior, 58: 164- 209.

[5] Fenwick Tara, Bierema Laura (2008). Corporate Social Responsibility: Issues for Human Resource Development Professionals, International Journal of training and Development, Vol. 12(1).

[6] K, Sandeep \& Balachandran Rakesh (2004). Corporate Social Responsibility as a determinant of Market Success: An Exploratory Analysis with Special Reference to MNCs in Emerging Markets, paper presented at IIM K- NASMEI International Conference.

[7] Malikarjunan K (2006). Best of HRM Practices, HRM Review, Vol. VI (2): 33- 34.

[8] Mees Adine \& Bonham Jamie (2004). Corporate Social Responsibility Belongs with HR, Canadian HR Reporter, Vol. 17( 7): 11

[9] Mehta Bindi (2003). Corporate Social Responsibility Initiatives of NSE NIFTY Companies: Content, Implementation, Strategies \& Impact, retrieved on September 15th, 2012 from http://www.nseindia. com/content/research/res_papers.

[10] Sirota Survey Intelligence (2007) quoted from CSR boosts employee engagement, Social responsibility boosts employee engagement 09 May, http://www. management-issues.com/2007/5/9/ research/social-responsibility-boosts-employee-engagement. asp

[11] Tripathi PC and Reddy PN (2006). Principles of Management, Tata McGraw Hill, New Delhi: 41. 